\title{
SEXUAL DISCRIMINATION AND FECUNDITY OF BARBEL STEED (HEMIBARBUS LABEO) IN THE JINJIANG RIVER, CHINA
}

\author{
TUO, Y. ${ }^{1,2}-$ LI, J. ${ }^{3}-$ XIAO, T. $.^{2 *}-$ WANG, H. $^{2}$ \\ ${ }^{1}$ College of Life Science and Resources Environment, Yichun University, Yichun 336000, China \\ ${ }^{2}$ Hunan Engineering Technology Research Center of Featured Aquatic Resources Utilization, \\ Hunan Agricultural University, Changsha 410128, China \\ ${ }^{3}$ College of Mathematics and Computer Science, Yichun University, Yichun 336000, China \\ *Corresponding author \\ e-mail:tyxiao1128@163.com \\ (Received 24 ${ }^{\text {th }}$ Nov 2020; accepted $3^{\text {rd }}$ Mar 2021)
}

\begin{abstract}
In order to establish a method to identify the sex of $H$. labeo by quantifying morphological characteristics and analyze their fecundity, 19 morphological characteristics and the condition factor from $180 \mathrm{H}$. labeo individuals (123 for modeling and 57 for verification) were collected from the Jinjiang River in China, were measured, standardized and analyzed; and 81 female individuals of $H$. labeo with stage III or IV of ovarian were randomly collected for analyzing fecundity in this study. Based on the data, six morphological characteristics were screened from the 19 total morphological characteristics by a stepwise discriminant method and used to establish discriminant equations. The correct identification rate was $93.50 \%$ and the verified accuracy rate was $91.23 \%$. The individual absolute fecundity $(F)$ of $H$. labeo in the Jinjiang River was $25945.57 \pm 19519.32$ eggs. The $F$ of $H$. labeo positively related to body weight, net weight, gonadal weight, and age, but negatively related with the body length, body weight $\times$ body length, maturity coefficient, and body fat. These results provided important reference information for the protection of wild $H$. labeo in the Jinjiang River.
\end{abstract}

Keywords: community ecology, heteromorphism, morphological discrimination, multivariate analysis, reproduction

\section{Introduction}

Sexual discrimination and fecundity are two fundamental research topics in fish population ecology and aquaculture, and their results provide important information to conserve wild fish resources and carry out artificial propagation (Macinnis and Corkum, 2000; McEvoy et al., 2009). Sexes can be distinguished by the differences in body size, body color, and secondary sex characteristics for fish with obvious heteromorphism (Jiang et al., 2019a, b). However, it is very hard to distinguish the sexes of fish that do not have obvious heteromorphism, such as Gadus morhua (McEvoy et al., 2009), Acrossocheilus wenchowensis (Xu et al., 2006), Acanthorhodeus chankaensi (Chen et al., 2013a), and Eryghroculter ilishaeformis (Chen et al., 2013b). Although anatomy and observation of gonad can accurately identify sex, there are a lot of limitations in the use of anatomy and other sex identification methods, which are not conducive to protecting studied fish and implement artificial reproduction. Ultrasound has been used for determining sex in some marine fish species (Davie et al., 2003; Glebe et al., 2003; McEvoy et al., 2009). However, this method does not suit to stream fish species. In addition, accuracy rates of this method are influenced by the maturity of fish (Martin et al., 1983). Methods that identify male and female individuals by quantitative indicators of body shape characteristics have been successfully applied in many fish, such as Ilisha 
elongate (Ni and Chen, 2003), Aniguilla japonica (Guo et al., 2011), Hemibarbus maculatus (Tuo et al., 2020), and Scatophagus argus (Wu et al., 2014). Applying discriminant equation established according to fish morphological characteristics, the accuracy of sex identification can be as high as 85\% (Guo et al., 2011; Wu et al., 2014).

Fecundity generally refers to the average number of mature eggs per female before spawning. Fecundity is an important biological characteristic, which reflects the adaptability of species or population to environmental changes and is related to the supplement of the population (Yatuha et al., 2018). Its change reflects the influence of the environment and adaptability of a population (Yin, 1995; Santangeli et al., 2017). Individual fecundity is not only related to genetic characteristics, environmental factors, nutritional status, and fishing pressure (Wootton, 1990; Niemuth and Klaper, 2015; Santangeli et al., 2017), but also related to biological indicators such as age, body length, and body weight (Macinnis and Corkum, 2000; He et al., 2007). The relationship between individual fecundity and its biological indexes can not only correctly evaluate the change of the fish population, but also provide a basis for the protection and management of fishery resources.

Hemibarbus labeo is a cyprinid fish that occurs all over East Asia, such as eastern mainland China, Japan, and Korea (Lin et al., 2007; Wang et al., 2016). Most individuals of the species are bottom-dwellers in streams and feed on aquatic insects (Lin et al., 2007). Unfortunately, due to habitat destruction and human overconsumption, its wild populations have been seriously threatened in the past decades (Lin et al., 2007). Although polymorphic microsatellite loci in the fish have been isolated and characterized, their population structures, especially sex composition and fecundity of their populations are still rarely investigated. One of the main reasons that block the investigation is there is no obvious difference in external morphology between male and female $H$. labeo. To provide technical support for the sex investigation of $H$. labeo, we established a technical method to identify the sex of $H$. labeo by quantifying its morphological characteristics, and we also analyzed the fecundity of $H$. labeo in the present study. Our results provided an important technical reference for the investigation and conservation of $H$. labeo population.

\section{Materials and methods}

\section{Study area}

Jinjiang River is a first-class tributary on the left bank of the lower reaches of the Ganjiang River. The basin is in the western part of Jiangxi Province. The average river width of the sampling section is $126.46 \mathrm{~m}$, and the average flow velocity is $0.21 \mathrm{~m} / \mathrm{s}$. The average water depth of the nearshore is $0.77 \mathrm{~m}$. The river is sand and gravel bottom, and the water quality is national class III according to the Environmental Quality Standards for Surface Water of China (GB 3838-2002).

\section{Sample collection}

The animal study was reviewed and approved by the Institutional Animal Care and Use Committee (IACUC) of Hunan Agricultural University (permit number 20171009). To sexual discrimination, a total of 123 individuals of $\mathrm{H}$. labeo were collected from the Shanggao section $\left(114^{\circ} 28^{\prime}-115^{\circ} 10^{\prime} \mathrm{E}, 28^{\circ} 02^{\prime}-28^{\circ} 25^{\prime} \mathrm{N}\right)$ of the Jinjiang River in Jiangxi Province of China from March to December 2014 for modeling. Other 57 
individuals of $\mathrm{H}$. labeo were collected at the same section of the Jinjiang River from January to November 2015 for verification. To analyze fecundity, 81 female individuals of $\mathrm{H}$. labeo with stage III or IV of ovarian maturity were randomly collected from the Shanggao section of the Jinjiang River from March to December 2014. The fish samples were caught by screen meshes (the mesh size is $2 \mathrm{~cm}$ ), ground cages (the mesh size is $0.5 \mathrm{~cm}$ ), and electrofishing techniques. The samples were put into a container with oxygen pumps for continuously oxygenation and quickly transported to the laboratory for temporary feeding. Before morphological measuring, the samples were anesthetized by anesthetics MS-222 (50 mg/L) for $5 \mathrm{~min}$.

\section{Morphological analysis}

Body length $(L)$, head length $\left(L_{\mathrm{HL}}\right)$, head height $\left(L_{\mathrm{HH}}\right)$, head width $\left(L_{\mathrm{HW}}\right)$, snout length $\left(L_{\mathrm{SL}}\right)$, postorbital length $\left(L_{\mathrm{PL}}\right)$, eye diameter $\left(L_{\mathrm{ED}}\right)$, interorbital width $\left(L_{\mathrm{IW}}\right)$, mouth breadth $\left(L_{\mathrm{MB}}\right)$, mouth length $\left(L_{\mathrm{ML}}\right)$, body highness $\left(L_{\mathrm{BH}}\right)$, caudal peduncle length $\left(L_{\mathrm{CL}}\right)$, caudal peduncle height $\left(L_{\mathrm{CH}}\right)$, the distance between snout and pelvic fin $\left(L_{\mathrm{PSL}}\right)$, pectoral fin length $\left(L_{\mathrm{PFL}}\right)$, caudal fin length $\left(L_{\mathrm{CFL}}\right)$, the distance between snout and dorsal fin $\left(L_{\mathrm{DSL}}\right)$, dorsal fin coxal length $\left(L_{\mathrm{DFL}}\right)$, and the distance between pelvic fin and anal fin ( $\left.L_{\mathrm{PAFD}}\right)$ of each sampled individual were measured using a ruler and Vernier calipers (Fig. 1). Then the fish samples were dissected and distinguished male and female through naked eye observation of their gonads. Gonads of the samples that could not be sex identified were fixed by $10 \%$ formalin solution and identified their sex through histological observation as previous studies (Li et al., 2000; Blazer, 2002). Bodyweight $(W)$, gland weight $\left(W_{\mathrm{g}}\right)$, and net weight $\left(W_{n}\right)$ were weighed by ML-T precision electronic balance with $0.01 \mathrm{~g}$ of the accuracy (Mettler Toledo, Switzerland). The data were accurate to two decimal places. The condition factor $(K)$, and gender heteromorphic index (GHI) were calculated as Equations 1 and 2:

$$
\begin{gathered}
K=100 \times \frac{W}{L^{3}} \\
G H I=1-\frac{L_{\min }}{L_{\max }}
\end{gathered}
$$

where $K$ was the condition factor, $W$ was body weight, $L$ was body length, $G S I$ was the gonadosomatic index, $\overline{L_{m i n}}$ was the mean of the body length of the fish with shorter body length, and $\overline{L_{\max }}$ was the mean of the body length of the fish with longer body length.

To overcome the influence of individual size differences on the local morphological characteristics, the 18 proportional morphological characteristics were calculated by dividing the measured morphological data of each fish by its body length.

\section{Fecundity analysis}

Fecundity was calculated by weight method (Ni, 2000), i.e. took the whole ovary and weighed, then counted all the eggs that begin to deposit yolk or had already deposited yolk of $0.1-0.5 \mathrm{~g}$ front, middle and rear ovary, respectively. The individual absolute fecundity $(F)$ was calculated with the average value of the three parts of the ovary, i.e. $F=$ total number of eggs / (sample weight $\times$ whole ovary weight). The relative fecundity of body length $\left(F_{\mathrm{L}}\right)$, relative fecundity of body weight $\left(F_{\mathrm{W}}\right)$, maturity 
coefficient $(G S I)$, and body fat $(K)$ were calculated according to Equations 3, 4, 5, and 6, respectively:

$$
\begin{gathered}
F_{L}=\frac{F}{L} \\
F_{\mathrm{w}}=\frac{F}{W_{n}} \\
G S I=\frac{W_{\mathrm{g}}}{W} \times 100 \\
K=\frac{W}{L^{3}} \times 100
\end{gathered}
$$

where $F_{L}$ was the relative fecundity of body length, $F$ was the individual absolute fecundity, $L$ was the body length, $F_{w}$ was the relative fecundity of body weight, $W$ was the body weight, $W_{n}$ was the net weight, and $W_{g}$ was the gonadal weight.

Eight intact scales in the second row above the lateral line of the middle and anterior sides of the fresh fish were taken to age identification according to previous reports (Xie et al., 1988; Xu et al., 2009). After taking photos with DMBA300 microscope (Motic, China), the scale diameter and wheel diameters of scales were measured with Motic Images Advanced 3.2 software (Motic, China).

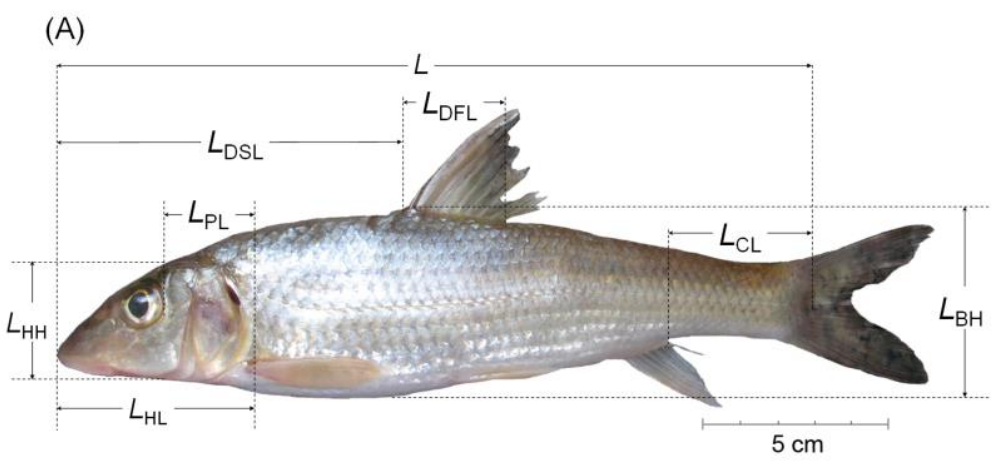

(B)

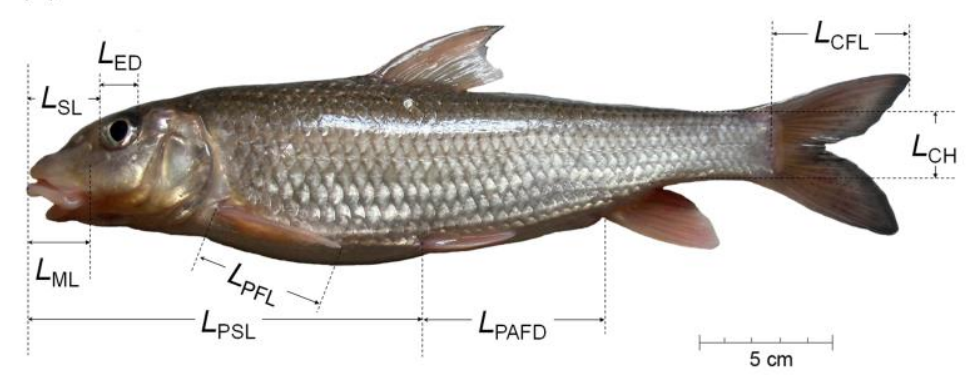

Figure 1. External morphologic images and morphological measurement characteristics of male (A) and female (B) H. labeo. All of 19 morphological characteristics of each sample were measured. $L$, body length; $L_{H L}$, head length; $L_{H H}$, head height; $L_{S L}$, snout length; $L_{P L}$, postortital length; $L_{E D}$, eye diameter; $L_{M L}$, mouth length; $L_{B H}$, body highness; $L_{C L}$, caudal peduncle length;

$L_{C H}$, caudal peduncle height; $L_{P S L}$, distance between snout and pelvic fin; $L_{P F L}$, pectoral fin length; $L_{C F L}$, caudal fin length; $L_{D S L}$, distance between snout and dorsal fin; $L_{D F L}$, dorsal fin coxal length; $L_{P A F D}$, distance between pelvic fin and anal fin 


\section{Data analysis}

Data were expressed as mean \pm standard deviation (S.D.). The comprehensive indexes with the largest eigenvalue vector were calculated and selected from the morphological characteristics. Kolmogorov-Smirnov test for normal distribution and Levene's Test for equality of variances was conducted firstly, then independent t-test was used to compare the body length, body weight and the comprehensive indexes of male and female, and One-way ANOVA with Tukey-Kramer post-hoc test was used to compare the fecundity indices among different age groups. The principal components with larger contribution rates were determined by the principal component analysis (PCA). Stepwise discriminant regression was used to further analyze and screen out the characteristics with significant differences between male and female populations, and the discriminant equations of female and male were established. Five correlation models (linear correlation, power correlation, exponential correlation, logarithmic correlation, quadratic correlation) were used to fit the relationship between individual fecundity and $\mathrm{L}, \mathrm{W}, \mathrm{Wn}, \mathrm{Wg}$, age, GSI, K, and L×W. The best correlation model was the one with the largest coefficient of determination $\mathrm{R} 2$. The multiple parameters between the individual fecundity and the biological indexes were described by multiple stepwise regression equation. All statistical analyses were completed by R (R Core Team, 2014) and SPSS 19 software. The significant level was set to $p=0.05$.

\section{Results and discussion}

\section{Morphological characteristics and sexual discrimination}

The body lengths of the female modeling samples (50/123) were ranged from 13.00 to $29.00 \mathrm{~cm}(20.90 \pm 3.39 \mathrm{~cm})$, and their body weights were range from 43.10 to $432.88 \mathrm{~g}(202.07 \pm 103.26 \mathrm{~g})$. The body lengths of the male modeling samples (73/123) were ranged from 11.00 to $25.00 \mathrm{~cm}(17.17 \pm 3.17 \mathrm{~cm})$ and their body weights were ranged from 25.96 to $260.00 \mathrm{~g}(105.32 \pm 63.91 \mathrm{~g})$ (Table A1 in the Appendix). Although there were significant differences between female and male in body length (Independent t-test, $t=6.15, p<0.001$ ) and body weight (Independent t-test, $t=5.90, p<0.001$ ), there was a large overlap between male and female modeling H. labeo (Fig. 2). The GHI of the modeling group was 0.18 . The body lengths of the female verification samples (28/57) were ranged from 11.60 to $34.00 \mathrm{~cm}(20.75 \pm 4.23 \mathrm{~cm})$, and their body weights were range from 27.50 to $629.00 \mathrm{~g}(206.71 \pm 136.29 \mathrm{~g})$. The body lengths of the male verification samples (29/57) were ranged from 11.60 to $25.5 \mathrm{~cm}$ $(18.15 \pm 4.0 \mathrm{~cm})$, and their body weights were range from 25.50 to $361.10 \mathrm{~g}$ $(136.05 \pm 91.40 \mathrm{~g})$. Similarly, although there were significant differences between female and male in body length (Independent t-test, $t=2.63, p=0.011$ ) and body weight (Independent t-test, $t=2.44, p<0.018$ ), there was a large overlap between male and female verification $H$. labeo (Fig. 2). The GHI of the verification group was 0.13 .

The PCA of morphological characteristics of $H$. labeo samples showed that $86.38 \%$ of the variation was explained by the first two principal components extracted (Table 1). For the first principal component, $L, L_{\mathrm{HH}}, L_{\mathrm{HW}}, L_{\mathrm{SL}}, L_{\mathrm{PL}}, L_{\mathrm{IW}}, L_{\mathrm{BH}}, L_{\mathrm{PAFD}}, L_{\mathrm{PFL}}$, and $L_{\mathrm{DFL}}$ exhibited large negative load factors, and $K$ exhibited large negative load factors in the second principal component (Table 1). Most of the screened morphological characteristics were significantly different between female and male modeling samples. The scores of the first principal component of females and males were significantly 
different (independent $t$-test, $t=-5.47, P<0.001$ ), but no significant difference was detected in the second principal component (independent $t$-test, $t=-1.20, P>0.05$ ). Taking the first and second principal components as the $\mathrm{X}$ - and Y-axis, the male and female samples overlapped greatly, and only partial samples were distinguished (Fig. 3A).

(A)

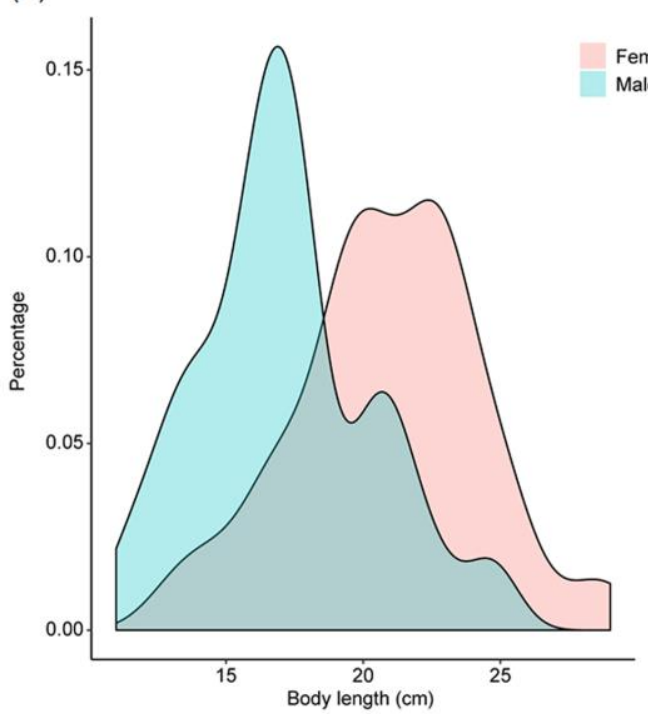

(C)

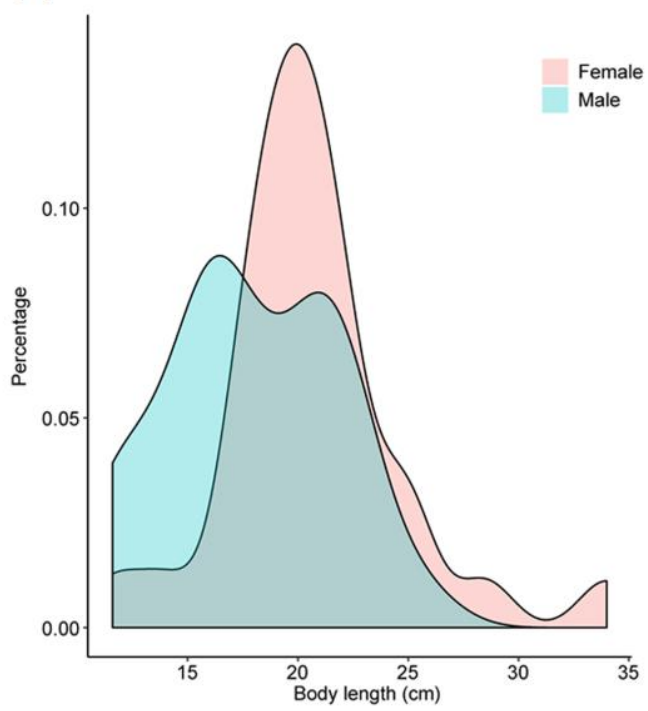

(B)

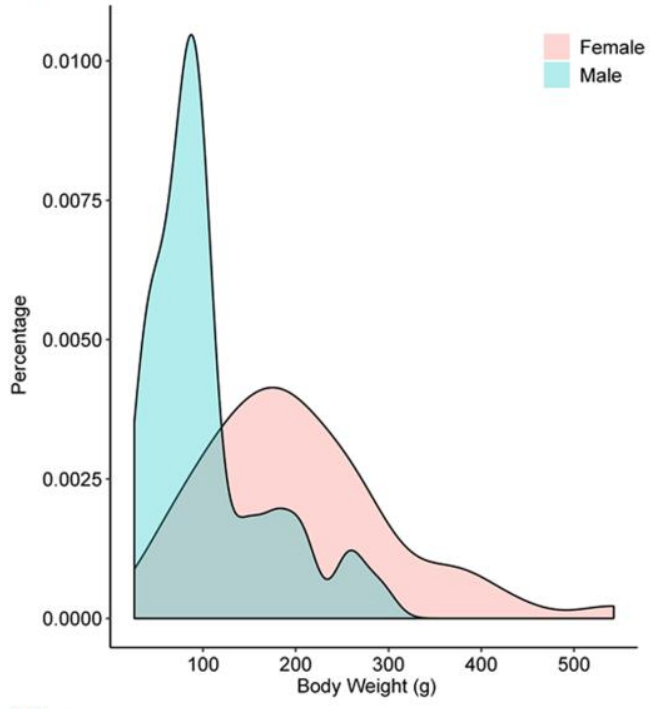

(D)

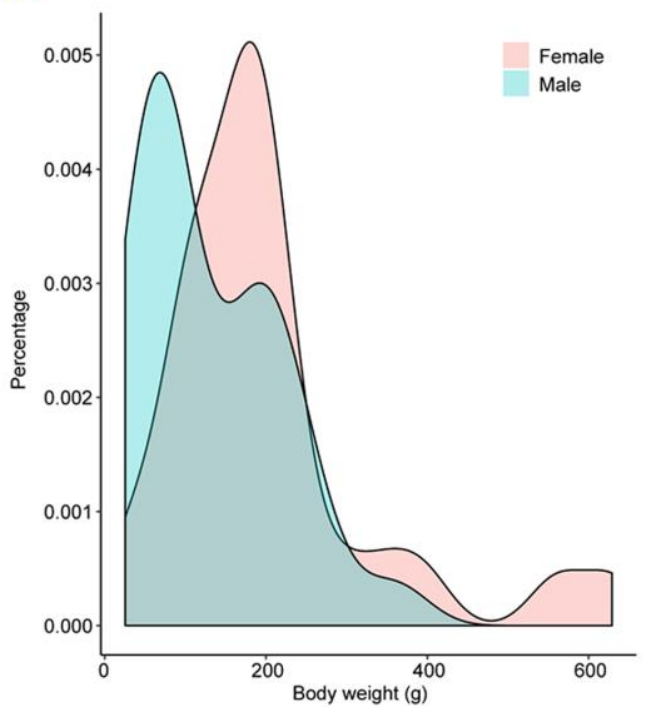

Figure 2. Body length and body weight distributions of male and female H. labeo. (A), density distributions of body length of modeling samples; $(B)$, density distributions of body weight of modeling samples; $(C)$, density distributions of body length of verification samples; $(D)$, density distributions of body weight of verification samples

Six morphological characteristics with significant discrimination effect of sex, i.e. $L_{\mathrm{PL}}, L_{\mathrm{MW}}, L_{\mathrm{BH}}, L_{\mathrm{CH}}, L_{\mathrm{PFL}}$, and $L_{\mathrm{DFL}}$, were screened from the 18 proportional morphological characteristics and condition factor through backward stepwise discriminant analysis (Wilks' Lambda: 0.3494; $\mathrm{F}(6,116)=35.9992, p<0.001$ ), and the discriminant formulas of $H$. labeo were established as Equations 7 and 8. 


$$
\begin{aligned}
& Y_{1}=-327.54+1143.57 L_{P L}+111.70 L_{M W}+89.83 L_{B H}+1047.57 L_{C H}+545.30 L_{P F L}+2352.36 L_{D F L} \\
& Y_{2}=-338.85+1296.42 L_{P L}+3.91 L_{M W}-27.26 L_{B H}+1351.29 L_{C H}+686.96 L_{P F L}+2192.87 L_{D F L}
\end{aligned}
$$

If $Y_{1}>Y_{2}$, the fish was female, otherwise it was male. The frequency distribution was obtained by calculating the discrimination score of each individual. It showed that the model could distinguish the sex of $H$. labeo (Fig. 3B). The six morphological characteristics of the 123 fish individuals were substituted into the discrimination equations, and $Y_{1}$ and $Y_{2}$ were calculated respectively for sex identification. After anatomical verification, only 8 samples were misjudged in terms of sex, with a misjudged rate of $6.5 \%$ (Table 2). The results of male and female discrimination of 57 $H$. labeo individuals in the verification group showed that the accuracy rate of male and female discrimination was $93.10 \%$ and $89.28 \%$, respectively, and the comprehensive accuracy rate was $91.23 \%$ (Table 3), which was consistent with previous studies in other fish (Ni and Chen, 2003; Guo et al., 2011; Wu et al., 2014).

Table 1. Loading factors of each morphological characteristics on the first two axes of principal component analysis

\begin{tabular}{c|c|c}
\hline \multirow{2}{*}{ Morpholopical variables } & \multicolumn{2}{|c}{ Loading factor } \\
\cline { 2 - 3 } & $\mathbf{P 1}$ & $\mathbf{P 2}$ \\
\hline$L$ & -0.98 & 0.12 \\
$L_{\mathrm{HL}}$ & -0.90 & 0.15 \\
$L_{\mathrm{HH}}$ & -0.97 & -0.03 \\
$L_{\mathrm{HW}}$ & -0.94 & -0.08 \\
$L_{\mathrm{SL}}$ & -0.93 & 0.09 \\
$L_{\mathrm{PL}}$ & -0.94 & 0.03 \\
$L_{\mathrm{IW}}$ & -0.95 & -0.16 \\
$L_{\mathrm{ED}}$ & -0.84 & 0.17 \\
$L_{\mathrm{MB}}$ & -0.89 & 0.06 \\
$L_{\mathrm{ML}}$ & -0.88 & -0.15 \\
$L_{\mathrm{BH}}$ & -0.92 & -0.28 \\
$L_{\mathrm{CL}}$ & -0.81 & -0.13 \\
$L_{\mathrm{CH}}$ & -0.97 & -0.07 \\
$L_{\mathrm{PSL}}$ & -0.93 & 0.20 \\
$L_{\mathrm{PFL}}$ & -0.93 & 0.00 \\
$L_{\mathrm{CFL}}$ & -0.91 & -0.05 \\
$L_{\mathrm{DSL}}$ & -0.94 & 0.16 \\
$L_{\mathrm{DFL}}$ & -0.94 & 0.12 \\
$L_{\mathrm{PAFD}}$ & -0.84 & 0.19 \\
$K$ & -0.34 & -0.90 \\
Variance explained & $80.53 \%$ & $5.85 \%$ \\
\hline
\end{tabular}

Morphological characteristics with the main contribution to each factor are highlighted by bold

L, body length; $\mathrm{L}_{\mathrm{HL}}$, head length; $\mathrm{L}_{\mathrm{HH}}$, head height; $\mathrm{L}_{\mathrm{HW}}$, head width; $\mathrm{L}_{\mathrm{SL}}$, snout length; LPL, postortital length; $\mathrm{L}_{\mathrm{IW}}$, interorbital width; $\mathrm{L}_{\mathrm{ED}}$, eye diameter; $\mathrm{L}_{\mathrm{ML}}$, mouth length; $\mathrm{L}_{\mathrm{MB}}$, mouth breadth; $\mathrm{L}_{\mathrm{BH}}$, body highness; $\mathrm{L}_{\mathrm{CL}}$, caudal peduncle length; $\mathrm{L}_{\mathrm{CH}}$, caudal peduncle height; LPS, distance between snout and pelvic fin; $\mathrm{L}_{\mathrm{PFL}}$, pectoral fin length; $\mathrm{L}_{\mathrm{CFL}}$, caudal fin length; $\mathrm{L}_{\mathrm{DSL}}$, distance between snout and dorsal fin; $\mathrm{L}_{\mathrm{DFL}}$, dorsal fin coxal length; LPAFD, distance between pelvic fin and anal fin; K, condition factor 
(A)

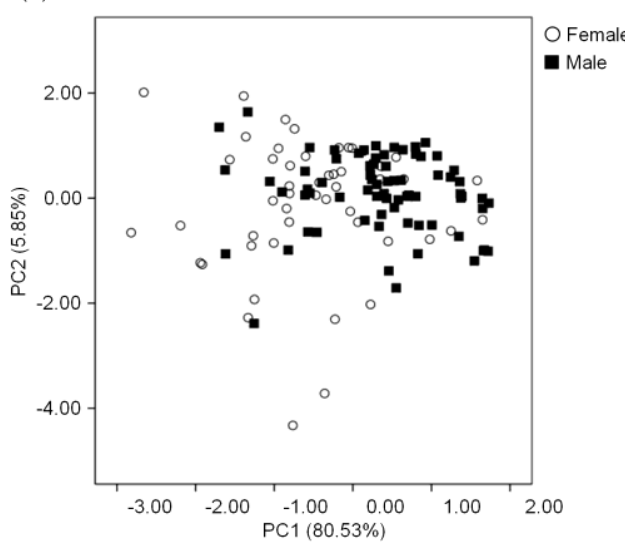

(B)

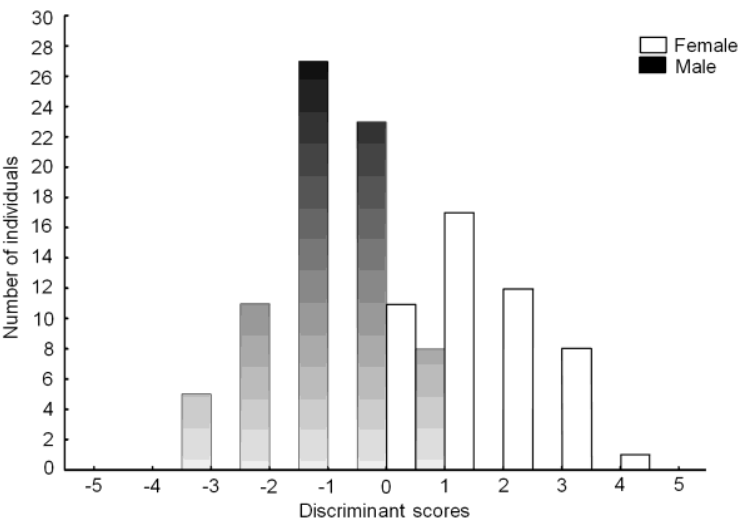

Figure 3. Principal component analysis profile $(A)$ and frequency distribution of discrimination values of stepwise discriminant function analysis $(B)$

Table 2. Discriminant analysis results of stepwise discriminant function analysis based on standardized morphological data of $\mathrm{H}$. labeo

\begin{tabular}{c|c|c|c|c|c}
\hline \multirow{2}{*}{ Sex } & \multirow{2}{*}{ Identified sex } & \multicolumn{2}{|c|}{ Predicted result } & \multirow{2}{*}{$\begin{array}{c}\text { Accuracy of } \\
\text { discrimination (\%) }\end{array}$} & $\begin{array}{c}\text { Total accuracy of } \\
\text { discrimination (\%) }\end{array}$ \\
\cline { 3 - 4 } Male & 73 & 71 & + & 97.26 & 93.50 \\
Female & 50 & 44 & 6 & 88 & \\
\hline
\end{tabular}

Table 3. Results of discriminant verification for $57 \mathrm{H}$. labeo samples

\begin{tabular}{|c|c|c|c|c|c|}
\hline \multirow{2}{*}{ Sex } & \multirow{2}{*}{ Identified sex } & \multicolumn{2}{|c|}{ Predicted result } & \multirow{2}{*}{$\begin{array}{c}\text { Accuracy of } \\
\text { discrimination }(\%)\end{array}$} & \multirow{2}{*}{$\begin{array}{c}\text { Total accuracy of } \\
\text { discrimination }(\%)\end{array}$} \\
\hline & & Male & Female & & \\
\hline Male & 29 & 27 & 2 & 93.10 & \\
\hline Female & 28 & 25 & 3 & 89.29 & 91.25 \\
\hline
\end{tabular}

As an important issue of fish reproductive capacity, sex ratio and sex differences in behavior have always been concerned by fish ecologists and aquaculture experts (Teixeira and Musick, 2001; Kumar et al., 2006). Identification of fish sex is an important prerequisite for calculating the sex ratio of the fish. However, for fish that does not have obvious heteromorphism, there was no suitable method to identify the sex of freshwater fish living in stream except for anatomical identification and ultrasonic identification of the sex for marine fish. Our results provided an accurate method to identify the sex of $H$. labeo. However, the data collection of fish morphology is still tedious work, which also limits the wide application of the current method of sex distinguish by quantitative morphological characteristics. In view of the development of computer technology, especially the automatic image recognition technology (Reeder et al., 2004), the development of automatic recognition and acquisition of fish morphological data technology methods and software will greatly make up for the shortcomings of the technology and contribute to the wide application of the technology. In addition, although our results showed that using six morphological characteristics with significant discrimination the effect could distinguish the sex of $H$. 
labeo, considering fish morphological parameters probably changed with the environment changes (Poulet et al., 2005; Michel et al., 2017), whether the discriminant formulas suited for other $H$. labeo living in other habitats still needs further verification.

\section{Biological indices and individual fecundity of $\mathrm{H}$. labeo}

A total of 81 female $H$. labeo individuals were analyzed. The individuals were composed of six ages and were mainly $1^{+}$and $2^{+}$age (Table Al). The minimum age of sexual maturity was $0^{+}$. The average body length and body weight of all female individuals were $20.82 \pm 4.26 \mathrm{~cm}$, and $207.11 \pm 133.39 \mathrm{~g}$, respectively. The $F, F_{L}$, and $F_{w}$ ranged from 1142.20 to $87047.68(25945.57 \pm 19519.32)$ eggs, 96.80 to 3481.90 $(1158.88 \pm 716.48)$ eggs per $\mathrm{cm}$, and 13.03 to $296.32(126.29 \pm 62.09)$ eggs per gonad. There were significant differences in the $F$ (one-way ANOVA, $F=12.877, \mathrm{p}<0.001$ ) and $F_{\mathrm{L}}$ (one-way ANOVA, $F=7.096, p<0.001$ ) among different age groups, and the $F$ and $F_{L}$ increased with age (Table Al). There was no significant difference in the $F_{\mathrm{W}}$ among different age groups (one-way ANOVA, $F=1.063, P>0.05$ ). The $F$ and $F_{L}$ increased with age, while the $F_{W}$ fluctuated with age in a certain range (Table Al). The results of correlation analysis between the $F$ and biological indexes of $H$. labeo showed that the $F$ had a power correlation with the GSI and $K$, quadratic correlation with body weight and net weight, linear correlation with body length, gonad weight, body length $\times$ body weight, and age (Fig. 4; Table A2).

(A)

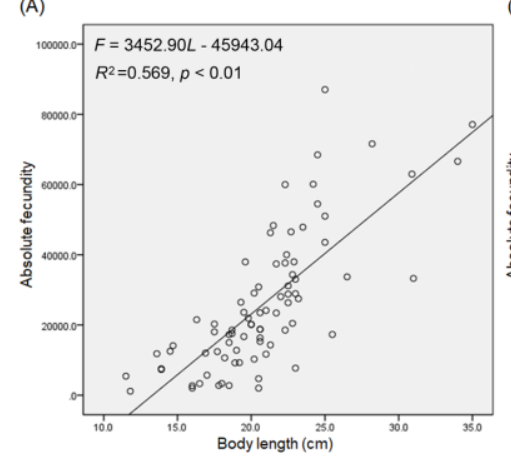

(D)

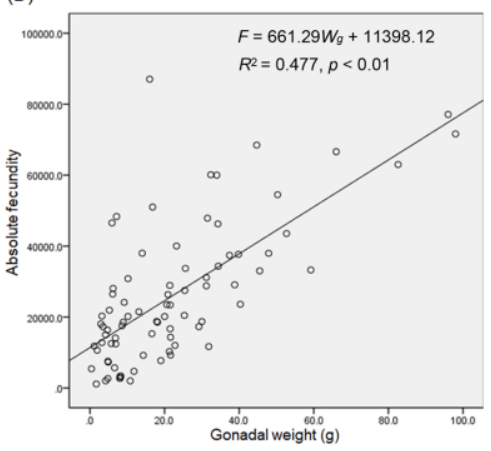

(B)

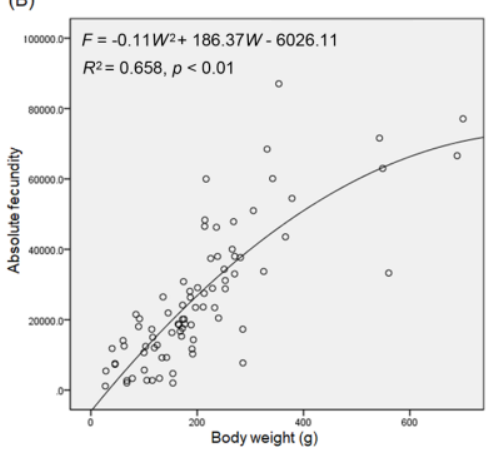

(E)

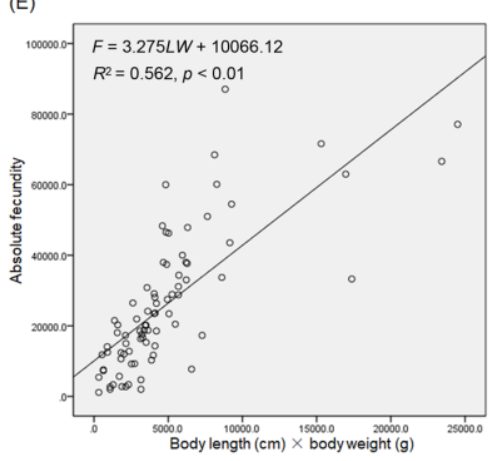

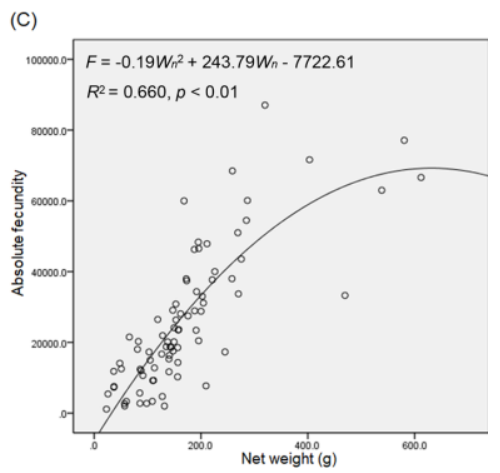

(F)

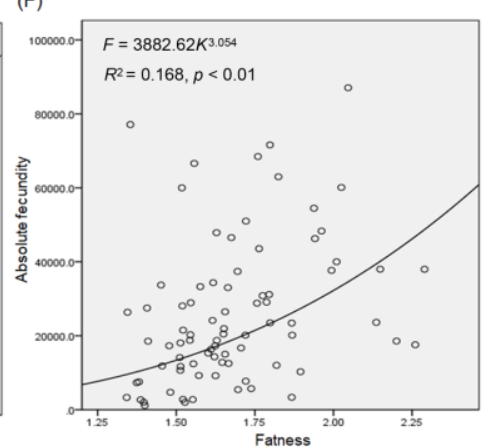

Figure 4. Correlation between absolute fecundity and biological indices of H. labeo in the Jinjiang River. F, absolute fecundity

The sexual maturity age of $H$. labeo was more than $4^{+}$years in Heilongjiang River basin (Nicholsky, 1960), and it was $2^{+}$years in the Yangtze River and its tributaries 
(Department of Fish Research, Hubei Institute of Hydrobiology, 1976). Our results showed that sexual maturity age of $H$. labeo in the Jinjiang River was $1^{+}$year, which indicated that the sexual maturity age of $H$. labeo in the Jinjiang River was younger. Comparing with other fish species in the same genus, the sexual maturity age of $H$. labeo in the Jinjiang River was the same with $H$. medius in the Beijing River in Guangdong of China (Lan et al., 2010), and H. maculates in the South Lake in Wuchang of China (Gong et al., 1990) and in the Yuanhe River in Jiangxi of China (Tuo, 2013), which showed that the adaptation mechanism of Hemibarbus in river and lake that locate at the middle reach of the Yangtze River under the current environmental pressure and fishing pressure, because of females from populations with high predation pressure mature earlier and at a smaller size (Reznick et al., 2004). Increasing the number of breeding population was conducive to the generation of more offspring, to supplement the shortage of natural population. The relative fecundity is used to reflect the reproductive strategies of fish (Yin, 1995). The higher $F_{W}$ indicated that the eggs of $H$. labeo in the Jinjiang River were a small size and large amount. The lack of nutrients might lead to less yolk accumulation. Simultaneously, it reflected the compensatory adaptation of $\mathrm{H}$. labeo in the Jinjiang River to environmental changes. This was a natural reproduction strategy formed under specific environmental conditions (Zúñiga-Vega et al., 2017). It showed the current situation of resource decline. The breeding strategy of $H$. labeo in the Jinjiang River tended to r-strategy to resist environmental pressure and ensure the continuation of the race.

\section{Multiple parameter relationships between the individual fecundity and biological indexes of H. labeo}

The relationship between the $F$ and the $L, W, W_{n}, W_{g}$, age, $G S I, K$, and $L \times W$ was fitted by multiple regression analysis, and the regression equation was as Equation 9 with $\mathrm{R}^{2}=0.689(\mathrm{~N}=81)$.

$F=38718.49-2828.99 L+312.39 W+216.18 W_{n}+53.54 W_{g}-9.08 W \times L+730.75$ age-126.62GSI-8093.95K $\quad$ (Eq.9)

The stepwise regression equation between the $\mathrm{F}$ and biological indexes was as Equation 10 with $\mathrm{R}^{2}=0.665(\mathrm{~N}=81)$.

$$
F=-7080.098+265.282 W-4.520 W \times L
$$

Equation 9 showed that the $F$ increased with the increase of $W, W_{\mathrm{n}}, W_{\mathrm{g}}$, and age, but decreased with the increase of $L, W \times L, G S I$, and $K$. Equation 10 showed that the $F$ was positively correlated with the $W$ and negatively correlated with the $W \times L$.

The individual fecundity of fish is not only related to the essential characteristics of species and environmental conditions, but also significantly related to biological indicators (Kraus et al., 2000; Macinnis and Corkum, 2000; Vrtilek and Reichard, 2016). Our results showed that the $F$ was positively quadratic correlated with $W$ and $W_{n}$, which was similar to Hemibarbus maculates (Tuo, 2013), Pelteobagrus fulvidraco (Liu, 1997), Schizothorax lissolabiatus (Xiao and Dai, 2010), and Opsariichthy sbidens (Li et al., 2010). The relationship between the $F$ of $H$. labeo in the Jinjiang River and body fat was not significant, which was similar to Coregonus ussurinsis (Dong et al., 1997), Pseudosciaena crocea (Zheng and Xu, 1964), Culter albumus (Wang et al., 2007), and 
Xenocyprism icrolepis (Liu et al., 2010). Our results also showed that the $F$ of $H$. labeo in the Jinjiang River was significantly affected by the biological index of $W$. Therefore, the relationship between body weight and fecundity could be used to predict the absolute fecundity of $H$. labeo in the Jinjiang River.

\section{Distribution of egg diameter and spawning type of $\mathrm{H}$. labeo}

The frequency analysis of egg diameter distribution showed that there were two egg diameter groups in stage III ovary of $\mathrm{H}$. labeo (Fig. 5A). The range of egg diameters of $H$. labeo in stage III ovary was $0.53-1.50(1.18 \pm 0.40) \mathrm{mm}$. The frequency distribution of egg diameter in stage IV ovary showed a three-peak pattern. The ranges from left peak to right peak were $0.50-1.20 \mathrm{~mm}, 1.25-1.60 \mathrm{~mm}$, and $1.7-2.15 \mathrm{~mm}$ (Fig. 5B), which were the 3 phases, 4 phases, and 5 phases of ovum, respectively. According to the variation trend of the maturity coefficient and the duration of the breeding period, it could be preliminarily inferred that the annual oviposition of $H$. labeo was three times.

(A)

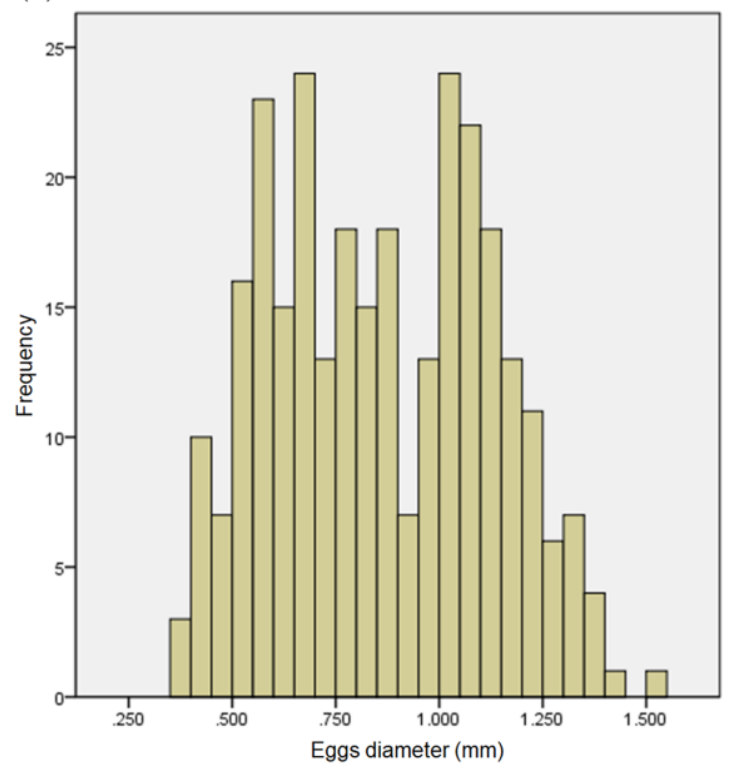

(B)

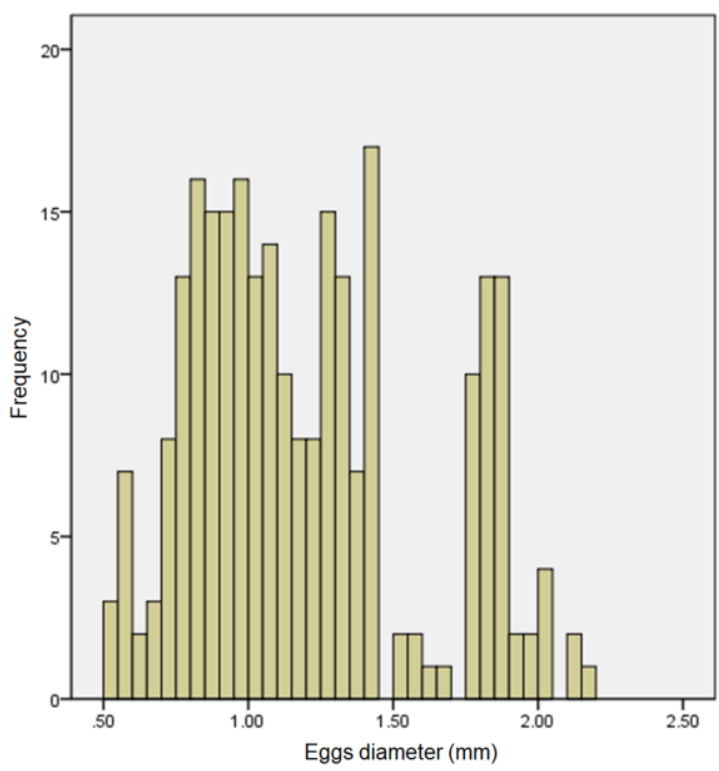

Figure 5. Distribution of eggs diameter of $H$. Labeo with III (A) and IV (B) maturity stages of ovaries

\section{Conclusion}

Using six morphological characteristics with a significant discrimination effect could distinguish the sex of $H$. labeo, and the comprehensive accuracy rate was $91.23 \%$. The $F, F_{L}$, and $F_{w}$ of $H$. labeo in the Jinjiang River ranged from 1142.20 to 87047.68 (25945.57 \pm 19519.32$), 96.80$ to $3481.90(1158.88 \pm 716.48)$ per $\mathrm{cm}$, and 13.03 to $296.32(126.29 \pm 62.09)$ per g. The $F$ of $H$. labeo in the Jinjiang River increased with the increase of $W, W_{\mathrm{n}}, W_{\mathrm{g}}$, and age, but decreased with the increase of $L, W \times L, G S I$, and $K$. However, whether the discriminant formulas suited for $H$. labeo living in other habitats still needs further verification. In addition, based on the results of this study, the automatic identification of sex and the automatic evaluation of fecundity of $H$. labeo need to be further studied. 
Acknowledgements. This study was supported by the Jiangxi Education Department in Science and Technology Project (GJJ190831), and the Innovation and Demonstration of Breeding Mode in Pond Healthy Colleges and Universities (2017NK1032). The authors thank Dr. Jiajia Ni at Guangdong Meilikang Bio-Science Ltd. (China) for assistance with data re-analysis.

\section{REFERENCES}

[1] Blazer, V. S. (2002): Histopathological assessment of gonadal tissue in wild fishes. - Fish Physiology and Biochemistry 26: 85-101.

[2] Chen, S., Zhao, R., Qi, D., Fan, X., Lei, H., Lin, Z. (2013a): Sexual dimorphism in morphological traits and female individual fecundity of Acanthorhodeus chankaensis Dybowsky. - Journal of Shanghai Jiaotong University (Agriculture Science) 31: 6166,78 .

[3] Chen, S., Zhao, R., Zhang, Y., Fan, X., Ding, G., Lin, Z. (2013b): Sexual dimorphism in morphology and female fecundity of Erythroculter ilishaeformis from rivers in Yuyao. Journal of Lishui University 35: 11-15.

[4] Davie, A., Porter, M. J. R., Bromage, N. R. (2003): Photoperiod manipulation of maturation and growth of Atlantic cod (Gadus morhua). - Fish Physiology and Biochemistry 28: 399-401.

[5] Department of Fish Research, Hubei Institute of Hydrobiology (1976): Fishes of the Yangtze River. - Science Press, Beijing, 79-80 pp.

[6] Dong, C. Z., Xia, Z. Z., Jiang, Z. F., Zhao, C. G., Wang, J., Zhu, Z. (1997): The tentative studies on reproduction population structure of Coregonus ussurinsisberg. - Chinese Journal Fishery 10(1): 14-21.

[7] Glebe, B., Harmon, P., Quinton, C. (2003): Early and ongoing studies on maturation of cage-reared Atlantic salmon in the Bay of Fundy. - Bulletin of the Aquaculture Association of Canada 103: 13-18.

[8] Gong, S., Ku, Y., Liang, K. (1990): A study of individual fecundity of the Hemibarbus maculatus (Bleeker) in South Lake Wuchang. - Journal of Huazhong Agriculture University 9(2): 204-208.

[9] Guo, H., Wei, K., Xie, Z., Tang, W., Shen, L., Gu, S., Wu, J., Chen, W. (2011): Analysis of morphological index system and discrimination of male and female silver eels (Anguilla japonica) collected at the Yangtze River Estuary. - Journal of Fishery of China 35: 1-9.

[10] He, Z., Zhou, Y., Xu, K., Zhang, H., Xue, L. (2007): Analyzing on the relationship between the individual fecundity and the biological indicators of Muraenesox cinereus. Marine Fishery 29(2): 134-139.

[11] Jiang, H., Liu, S., Xiao, T. Y., Cao, Y. K., Xie, M., Yin, Z. F. (2019b): Cellular biological and eumelanin-related gene expressional based of pigment deviation of Leptobotia taeniops. - Applied Ecology and Environmental Research 17: 12181-12189.

[12] Jiang, H., Liu, S., Xiao, T. Y., Xie, M. (2019a): Body color regulation of Leptobotia taeniops through tyrosinase gene expression. - Applied Ecology and Environmental Research 17: 5525-5537.

[13] Kraus, G., Müller, A., Trella, K., Köuster, F. W. (2000): Fecundity of Baltic cod: temporal and spatial variation. - Journal of Fish Biology 56(6): 1327-1341.

[14] Kumar, K., Bisht, K. L., Dobriyal, A. K., Joshi, H. K., Bahuguna, P. K., Goswami, S., Balodi, V. P., Thapliyal, A. (2006): Fecundity and sex ratio in a rate hill-stream fish Botia dayi (Hora) from Garhwal Himalaya, Uttaranchal. - Uttar Pradesh Journal of Zoology 26: 271-276.

[15] Lan, Z.-J., Li, Q., Zhao, J., Zhong, L.-M., Chen, L.-X. (2010): Reproductive biology of Hemibarbus medius in the Beijiang River. - Acta Hydrobiologica Sinica 34(5): 10371042. 
[16] Li, Q., Osada, M., Mori, K. (2000): Seasonal biochemical variations in Pacific oyster gonadal tissue during sexual maturation. - Fishery Science 66: 502-508.

[17] Li, Q., Lan, Z., Zhao, J., Chen, L., Zhong, L., Yi, Z., Shu, H., Li, H. (2010): Study on individual fecundity of Opsariichthys bidens of the Beijiang River in Guangdong Province. - Sichuan Journal of Zoology 29(3): 440-445.

[18] Lin, C. J., Wang, J. P., Lin, H. D., Chiang, T. Y. (2007): Isolation and characterization of polymorphic microsatellite loci in Hemibarbus labeo (Cyprinidae) using PCR-based isolation of microsatellite arrays (PIMA). - Molecular Ecology Notes 7: 788-790.

[19] Liu, S. P. (1997): A study on the biology of Pseudobagrus fulvidraco in Poyang Lake. Chinese Journal of Zoology 32(4): 11-17.

[20] Liu, M., Xiong, B. X., Lv, G. J. (2010): Preliminary studies on reproduction biology of Xenocypris microlepis. - Journal of Hydroecology 3(1): 76-81.

[21] Macinnis, A. J., Corkum, L. D. (2000): Fecundity and reproductive season of the round goby Neogobium melanostomus in the upper Detroit River. - Transactions of the American Fisheries Society 129(1): 136-144.

[22] Martin, R. W., Myers, S., Sower, S. A., Phillips, D. J., McAuley, C. (1983): Ultrasonic imaging, a potential tool for sex determination of live fish. - North American Journal of Fisheries Management 3: 258-264.

[23] McEvoy, F. J., Tomkiewicz, J., Støttrup, J. G., Overton, J. L., McEvoy, C., Svalastoga, E. (2009): Determination of fish gender using fractal analysis of ultrasound images. Veterinary Radiology \& Ultrasound 50: 519-524.

[24] Michel, M. J., Chien, H., Beachum, C. E., Bennett, M. G., Knouft, J. H. (2017): Climate change, hydrology, and fish morphology: predictions using phenotype-environment associations. - Climate Change 140: 563-576.

[25] Ni, H. (2000): Individual fecundity of Cynoglossus robustus from the East China Sea. Journal of Fishery of China 24(4): 318-323.

[26] Ni, H., Chen, X. (2003): Analysis of shape index system and discriminant of male and female of Ilisha elongate. - Journal of Biomathematics 18: 224-228.

[27] Nicholsky, B. (1960): Fishes in the Heilongjiang Basin. - Science Press, Beijing.

[28] Niemuth, N. J., Klaper, R. D. (2015): Emerging wastewater contaminant metformin causes intersex and reduced fecundity in fish. - Chemosphere 135: 38-45.

[29] Poulet, N., Reyjol, Y., Collier, H., Lek, S. (2005): Does fish scale morphology allow the identification of populations at a local scale? A case study for rostrum dace Leuciscus leuciscus burdigalensis in River Viaur (SW France). - Aquatic Science 67: 122-127.

[30] R Core Team (2014): R: A language and environment for statistical computing. - R Foundation for Statistical Computing, Vienna, Austria. URL: http://www.R-project.org.

[31] Reeder, D. B., Jech, J. M., Stanton, T. K. (2004): Broadband acoustic backscatter and high-resolution morphology of fish: measurement and modeling. - Journal of Acoustical Society of America 116: 747-761.

[32] Reznick, D. N., Bryant, M. J., Roff, D. A., Ghalambor, C. K., Ghalambor, D. E. (2004): Effect of extrinsic mortality on the evolution of senescence in guppies. - Nature 431: 1095-1099.

[33] Santangeli, S., Maradonna, F., Zanardini, M., Notarstefano, V., Gioacchini, G., FornerPiquer, I., Habibi, H., Carnevali, O. (2017): Effects of diisononyl phthalate on Danio rerio reproduction. - Environmental Pollution 231: 1051-1062.

[34] Teixeira, R. L., Musick, J. A. (2001): Reproduction and food habits of the lined seahorse, Hippocampus erectus (Teleostei: Syngnathidae) of Chesapeake Bay, Virginia. - Brazilian Journal of Biology 61: 79-90.

[35] Tuo, Y. (2013): Fecundity of Hemibarbus maculates in the Yuanhe River of Jiangxi, China. - Sichuan Journal of Zoology 32(3): 375-379.

[36] Tuo, Y., Xiao, T., Wang, H. (2020): Discrimination of sexual dimorphism through external morphology of spotted steed (Hemibarbus maculatus) in the Yuanhe River, China. - Applied Ecology and Environmental Research 18(1): 1539-1550. 
[37] Vrtilek, M., Reichard, M. (2016): Female fecundity traits in wild populations of African annual fish: the role of the aridity gradient. - Ecology and Evolution 6(16): 5921-5931.

[38] Wang, Y. D., Xiong, B. X., Ma, X. F., Xu, M. S., Zhang, L. L., Wang, X. B., Hu, Q. S. (2007): Fecundity of Culter dabryi in Daoguanhe Reservoir, Wuhan, China. Oceanologia et Limnologia Sinica 38(2): 180-186.

[39] Wang, H., Wu, X., Lv, Q., Su, S., Li, G., Lin, Y., Lu, Y., Meng, Y. (2016): Identification and description of the mitochondrial genome of Hemibarbus labeo (Cypriniformes: Cytrinidae). - Mitochondrial DNA A 27: 3886-3887.

[40] Wootton, R. J. (1990): Ecology of Teleost Fishes. - Springer, Netherlands, pp. 159-194.

[41] Wu, B., Zhang, M., Deng, S., Shi, S., Li, G., Zhu, C. (2014): Analysis of morphological index and discrimination of male and female Scatophagus argus. - Journal of Shanghai Ocean University 23: 64-69.

[42] Xiao, H., Dai, Y. G. (2010): Study on individual fecundity of Schizothorax lissolabiatus in the Beipan River. - Journal of Hydroecology 31(3): 64-70.

[43] Xie, C., Gong, S., Yang, Z., Zhang, Q. (1988): The growth of Hemibarbus maculatus Bleeker in Nanhu Lake, Wuchang. - Oceanologia et Limnologia Sinica 19(3): 225-231.

[44] Xu, D., Lin, Z., Lei, H. (2006): Sexual dimorphism in morphological traits and female individual fecundity of Acrossocheilus wenchowensis. - Journal of Shanghai Jiaotong University (Agriculture Science) 24: 335-340.

[45] Xu, W., Li, C., Geng, L., Sun, H., Liu, X. (2009): Growth and reproduction of reared Hemibarbus labeo in the Wusuli River. - Journal of Fishery Science of China 16(4): 550556.

[46] Yatuha, J., Rutaisire, J., Chapman, L., Kang'ombe, J., Sikawa, D. (2018): Reproductive strategies of smooth-head catfish Clarias liocephalus (Boulenger, 1898), in the RwiziRufuha wetland system, south-western Uganda. - African Journal of Aquatic Science 43(2): 101-109.

[47] Yin, M. (1995): Fish Ecology. - China Agriculture Press, Beijing, pp. 51-126.

[48] Zheng, W. L., Xu, G. Z. (1964): On the peculiarities of the individual fecundity of the large yellow croaker, Pseudosciaena crocea (Richardson), off Kuangching-Yang, Fukuen. - Journal of Fishery of China 1(1): 1-17.

[49] Zúñiga-Vega, J. J., Olivera-Tlahuel, C., Molina-Moctezuma, A. (2017): Superfetation increases total fecundity in a viviparous fish regardless of the ecological context. - Acta Oecologica-International Journal of Ecology 84: 48-56.

\section{APPENDIX}

Table A1. The biological indices and individual fecundity of H. labeo

\begin{tabular}{c|c|c|c|c|c|c|c}
\hline \multirow{2}{*}{ Biological indices } & \multicolumn{7}{c}{ Age } \\
\cline { 3 - 8 } & $\mathbf{0}^{+}$ & $\mathbf{1}^{+}$ & $\mathbf{2}^{+}$ & $\mathbf{3}^{+}$ & $\mathbf{4}^{+}$ & $\mathbf{5}^{+}$ \\
\hline \multicolumn{2}{c}{ Sample amount } & 2 & 21 & 33 & 16 & 4 & 5 \\
\hline \multirow{2}{*}{$L(\mathrm{~cm})$} & Mean \pm S.D. & $11.65 \pm 0.21$ & $17.46 \pm 2.37$ & $20.43 \pm 1.89$ & $23.01 \pm 2.14$ & $24.68 \pm 2.59$ & $31.08 \pm 4.10$ \\
\cline { 2 - 8 } & Range & $11.5-11.8$ & $13.6-20.6$ & $16.5-23.5$ & $18.3-26.5$ & $22.5-28.2$ & $24.5-35.0$ \\
\hline \multirow{2}{*}{$W(g)$} & Mean \pm S.D. & $27.65 \pm 0.78$ & $111.60 \pm 52.85$ & $184.51 \pm 56.62$ & $255.45 \pm 68.29$ & $331.12 \pm 160.51$ & $575.28 \pm 130.59$ \\
\cline { 2 - 8 } & Range & $27-28$ & $40-211$ & $78-281$ & $116-354$ & $187-543$ & $378-700$ \\
\hline \multirow{2}{*}{$W_{\mathrm{n}}(g)$} & Mean \pm S.D. & $24.40 \pm 1.98$ & $93.84 \pm 43.21$ & $149.05 \pm 42.83$ & $215.29 \pm 60.44$ & $255.00 \pm 111.39$ & $497.10 \pm 130.01$ \\
\cline { 2 - 8 } & Range & $23.0-25.8$ & $36.6-158.4$ & $60.3-225.9$ & $104.8-319.8$ & $153.2-403.2$ & $285.0-612$ \\
\hline \multirow{2}{*}{$W_{\mathrm{g}}(g)$} & Mean \pm S.D. & $1.05 \pm 0.92$ & $9.48 \pm 9.46$ & $20.76 \pm 13.01$ & $21.79 \pm 11.14$ & $48.25 \pm 36.35$ & $70.82 \pm 18.39$ \\
\cline { 2 - 8 } & Range & $0.4-1.7$ & $1.1-40.3$ & $3.2-47.9$ & $4.2-44.7$ & $20.9-98.0$ & $50.3-96.0$ \\
\hline \multirow{2}{*}{$G S I$} & Mean \pm S.D. & $4.47 \pm 4.13$ & $9.79 \pm 6.27$ & $13.43 \pm 7.00$ & $10.44 \pm 5.51$ & $17.11 \pm 5.80$ & $14.58 \pm 2.83$ \\
\cline { 2 - 8 } & Range & $1.55-7.39$ & $2.12-25.44$ & $2.83-27.78$ & $3.01-20.20$ & $11.38-24.31$ & $10.78-17.65$ \\
\hline
\end{tabular}




\begin{tabular}{|c|c|c|c|c|c|c|c|}
\hline \multirow{2}{*}{$K$} & Mean \pm S.D. & $1.55 \pm 0.21$ & $1.63 \pm 6.26$ & $1.70 \pm 0.19$ & $1.73 \pm 0.22$ & $1.61 \pm 0.22$ & $1.65 \pm 0.23$ \\
\hline & Range & $1.40-1.70$ & $1.37-2.26$ & $1.34-2.29$ & $1.41-2.15$ & $1.35-1.80$ & $1.35-1.94$ \\
\hline \multirow{2}{*}{$F$} & Mean \pm S.D. & $\begin{array}{c}3285.38 \pm \\
3030.92\end{array}$ & $\begin{array}{c}13409.47 \pm \\
7087.29 \\
\end{array}$ & $\begin{array}{c}21989.13 \pm \\
12873.63 \\
\end{array}$ & $\begin{array}{c}38930.96 \pm \\
22665.99 \\
\end{array}$ & $\begin{array}{c}42605.51 \pm \\
20767.20\end{array}$ & \\
\hline & Range & & & $\begin{array}{l}2785.44- \\
47876.85\end{array}$ & & & $\begin{array}{l}33276.32- \\
77107.20\end{array}$ \\
\hline \multirow{2}{*}{$\begin{array}{c}F_{\mathrm{L}} \\
\text { (amount } / \mathrm{cm} \text { ) }\end{array}$} & Mean \pm S.D. & $284.42 \pm 265.34$ & $762.48 \pm 374.30$ & $1043.54 \pm 570.67$ & $1665.24 \pm 912.92$ & $1677.38 \pm 627.19$ & $1899.57 \pm 475.03$ \\
\hline & Range & \begin{tabular}{|l|}
$96.80-$ \\
472.05 \\
\end{tabular} & \begin{tabular}{c|}
$98.01-$ \\
1319.64 \\
\end{tabular} & \begin{tabular}{|l|}
$156.49-$ \\
2172.33 \\
\end{tabular} & \begin{tabular}{|l|}
$335.56-$ \\
3481.91 \\
\end{tabular} & \begin{tabular}{|c|}
$1171.05-$ \\
2539.31 \\
\end{tabular} & \begin{tabular}{|l|}
$1073.43-$ \\
2223.88 \\
\end{tabular} \\
\hline \multirow{2}{*}{$F_{\mathrm{W}}($ amount $/ g)$} & Mean \pm S.D. & $117.34 \pm 106.32$ & $136.03 \pm 77.99$ & $119.90 \pm 48.72$ & $150.15 \pm 70.73$ & $129.56 \pm 9.24$ & $105.00 \pm 30.79$ \\
\hline & Range & \begin{tabular}{|l|}
$42.15-192.50$ \\
\end{tabular} & 13.03-296.32 & $25.99-195.98$ & $27.00-276.94$ & 118.99-140.92 & $59.40-144.03$ \\
\hline
\end{tabular}

$\mathrm{L}$, body length; $\mathrm{W}$, body weight; $\mathrm{W}_{\mathrm{n}}$, net weight; $\mathrm{W}_{\mathrm{g}}$, gonadal weight; $\mathrm{GSI}$, maturity coefficient; $\mathrm{K}$, body fat

Table A2. Regression equation between individual fecundity and single biological indices of H. Labeo in the Jinjiang River

\begin{tabular}{|c|c|c|c|}
\hline \multirow{2}{*}{$\begin{array}{l}\text { Biological } \\
\text { indices }\end{array}$} & \multicolumn{3}{|c|}{ Individual fecundity } \\
\hline & $F_{\mathbf{W}}$ & $F$ & $F_{\mathrm{L}}$ \\
\hline \multirow{2}{*}{$L(\mathrm{~cm})$} & \multirow{2}{*}{$P>0.05$} & $F=-45943.04+3452.90 L$ & $F=-2.25 L^{2}+202.04 L-2031.38$ \\
\hline & & $R^{2}=0.569, P<0.01$ & $R^{2}=0.374, P<0.01$ \\
\hline \multirow{2}{*}{$W(g)$} & \multirow{2}{*}{$P>0.05$} & $F=-0.11 W^{2}+186.37 W-6026.11$ & $F=-0.007 W^{2}+7.915 W-54.598$ \\
\hline & & $R^{2}=0.658, P<0.01$ & $R^{2}=0.486, P<0.01$ \\
\hline \multirow{2}{*}{$W_{\mathrm{n}}(g)$} & \multirow{2}{*}{$P>0.05$} & $F=-0.19 W_{\mathrm{n}}^{2}+243.79 W_{\mathrm{n}}-7722.61$ & $F=-0.01 W_{n}^{2}+10.02 W_{n}-102.38$ \\
\hline & & $R^{2}=0.660, P<0.01$ & $R^{2}=0.498, P<0.01$ \\
\hline \multirow{2}{*}{ Age } & \multirow{2}{*}{$P>0.05$} & $F=11480.47 t-10580.13$ & $F=-37.035 t^{2}+0.27 t-348.51$ \\
\hline & & $R^{2}=0.448, P<0.01$ & $R^{2}=0.299, P<0.01$ \\
\hline \multirow{2}{*}{$W_{\mathrm{g}}(\mathrm{g})$} & \multirow{2}{*}{$P>0.05$} & $F=661.29 W_{\mathrm{g}}+11398.12$ & $F=-0.127 W_{\mathrm{g}}{ }^{2}+29.69 W_{\mathrm{g}}+619.56$ \\
\hline & & $R^{2}=0.477, P<0.01$ & $R^{2}=0.325, P<0.01$ \\
\hline \multirow{2}{*}{$L \times W(\mathrm{~cm} * g)$} & \multirow{2}{*}{$P>0.05$} & $F=3.275 L W+10066.12$ & $F=-8.35 E+0.27 L W+224.53$ \\
\hline & & $R^{2}=0.562, P<0.01$ & $R^{2}=0.482, P<0.01$ \\
\hline \multirow{2}{*}{ GSI } & $\begin{array}{c}F=0.58 \mathrm{GSI}^{2}- \\
2.58 \mathrm{GSI}+7.58\end{array}$ & $F=11506 G S I^{0.039}$ & $F=618.09 G S I^{0.032}$ \\
\hline & $R^{2}=0.08, P<0.05$ & $R^{2}=0.075, P<0.05$ & $R^{2}=0.066, P<0.01$ \\
\hline \multirow{2}{*}{$K$} & \multirow{2}{*}{$P>0.05$} & $F=3882.62 K^{3.054}$ & $F=-1148.851 K^{2}+5540.21-4680.51$ \\
\hline & & $R^{2}=0.168, P<0.01$ & $R^{2}=0.190, P<0.01$ \\
\hline
\end{tabular}

L, body length; $\mathrm{W}$, body weight; $\mathrm{W}_{\mathrm{n}}$, net weight; $\mathrm{W}_{\mathrm{g}}$, gonadal weight; GSI, maturity coefficient; $\mathrm{K}$, body fat 